\title{
GLOBAL SENSITIVITY ANALYSIS FOR TRANSFORMATION OF HOEK-BROWN FAILURE CRITERION FOR ROCK MASS
}

\author{
Jan ŠTEFAŇÁK ${ }^{1}$, Zdeněk KALA ${ }^{2}{ }^{2}$, Lumír MIČA ${ }^{3}$, Arnoldas NORKUS ${ }^{*}$ \\ 1, ${ }^{3}$ Department of Geotechnics, Faculty of Civil Engineering, Brno University of Technology, \\ Veveři 95, 602 00, Brno, Czech Republic \\ ${ }^{2}$ Institute of Structural Mechanics, Faculty of Civil Engineering, Brno University of Technology, \\ Veveři 95, 602 00, Brno, Czech Republic \\ ${ }^{4}$ Geotechnical Laboratory, Vilnius Gediminas Technical University, Sauletekio al. 11, Vilnius 10223, Lithuania
}

Received 22 May 2018; accepted 19 June 2018

\begin{abstract}
A variety of engineering activities require reliable evaluation of rock strength. For instance, the stability of rock slopes depends on structural geology of rock massif in which the slope is excavated. Hoek-Brown (HB) failure criterion applied in rock design practice introduces factors based on the properties of jointed rock. The non-linear finite element safety calculation is conveniently used for calculation safety the factor of slope stability. The Mohr-Coulomb (MC) failure (strength) criterion for soil is widely applied in geotechnical design. Therefore, the appropriate transformation from HB to the equivalent MC, employing angle of shearing resistance $\varphi$ and cohesion $c$, is necessary. This article studies the effect of jointed rock massif properties on the transformed MC parameters by using Sobol's global sensitivity analysis (SSA) and HB transformation equations. Statistical parameters needed for the evaluation of sensitivity analysis are processed using classical statistical methods upon the emulation of Latin Hypercube Sampling simulation methods. Developed and adapted by authors techniques are illustrated by processing real rock investigation data from survey of the trachyte massif located in the Czech Republic. The first and higher order effects of random inputs are identified using SSA. It is illustrated that the effects of inputs on the MC parameters varies significantly depending on the discontinuity distribution and height of the slope.
\end{abstract}

Keywords: sensitivity analysis, reliability, statistical analysis, Latin hypercube sampling, jointed rock, rock sample, Hoek-Brown and Mohr-Coulomb failure criteria.

\section{Introduction}

Natural rock mass differs from most other engineering materials in the sense that it contains discontinuities such as joints, bedding planes, folds, sheared zones and faults, which render its structure discontinuity. Generally, the discontinuity can be described as a plane of weakness. According to Palmström (2002), strength of rock mass more often depend not on "effective" mechanical properties of homogenous rock volume but on geological deffects. Thefefore the relevant description and processing the data of dicontinuities in rock mass is more significant for considering rock mass response measures in geotechnical applications.

The Hoek-Brown (HB) failure criterion (Hoek et al. 2002) deals with the problems of modelling such rock masses, that naturally consist of discrete elements connected by joints, by the tools based on mechanics of con- tinua. The HB criterion introduces factors based on the geologically observed characteristics of joints to reduce the properties of intact rock. In practice widely used $\mathrm{HB}$ criterion was originally introduced as the deterministic one. The probabilistic approach is believed to be more adequate as it provides much more information than the standard deterministic point estimate. This idea is proved by the fact, that stochastic analyses studying the uncertainty associated with estimating the properties of rock mass are reported (e.g. Hoek 1998; Cai 2011; Lü, Low 2011; Li et al. 2012; Sari 2012).

The HB criterion deals with relatively high number of inputs, which values often scatter significantly. The identification of statistical characteristics of input variables is a key task especially for random variables whose impact on output is crucial. The crucial input random variables

*Corresponding author. E-mail: arnoldas.norkus@vgtu.lt 


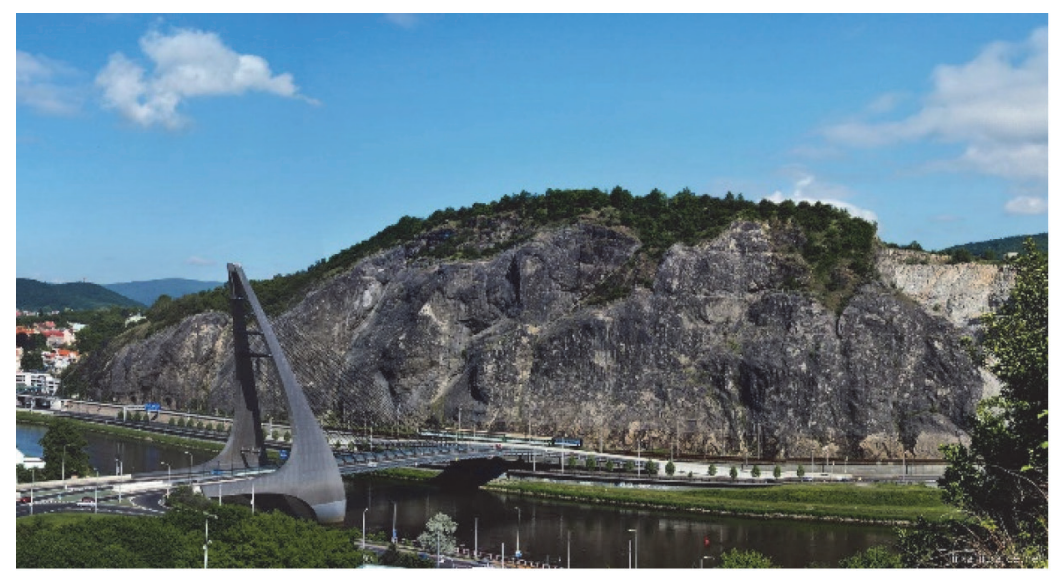

Figure 1. Analysed rock massif in Ústí nad Labem, Czech Republic (Author Mr. Jiř́ Jiráček)

can be identified by sensitivity analysis methods (Saltelli et al. 2004). Although it is not easy to precisely obtain statistical parameters for $\mathrm{HB}$ criterion, to the authors best knowledge none of the published papers studies the effect of inputs on the monitored outpus in the way of sensitivity analysis.

Hence, the authors of presented study decided to employ the Sobol's sensitivity analysis (SSA) (Sobol' 1993, 2001) to explore the effect of random variables used as input for defining the $\mathrm{HB}$ criterion. The monitored outputs are transformed Mohr-Coulomb (MC) criterion parameters $\varphi$ and $c$, that serve to determine equivalent rock strength. These outputs are obtained by fitting an average MC linear relationship to the nonlinear $\mathrm{HB}$ one. Such transformation is necessary in the case of non-linear finite element (FEM) safety calculation approach $(\varphi / c$ reduction). Safety calculations often are used in practice for the determining the factor of safety for rock slopes. Although the advanced constitutive models are applicable in the stress-strain calculations, in case of safety analysis these models will behave as a standard MC model (Brinkgreve, Bakker 1991), whose parameters have to be determined correctly.

One can mention variance-based methods (e.g. Saltelli et al. 2004) that can serve for practical applications (Borgonovo, Plischke 2016). The above-mentioned methods present simulated experiment, equivalent to design's analysis of experimental outcome (Saltelli et al. 2010).

From the scientific point of view, sensitivity analysis (SA) is a set of methods that allow us to understand the key findings of mathematical models (see e.g. Saltelli et al. 2004). Regarding issues of reliability in the building industry, SA is a significant part of reliability analysis of geotechnical tasks (Vessia et al. 2017), fatigue of materials (Pejkowski 2017), concrete structures (Liang et al. 2017) and steel structures (Kala, Valeš 2017a, 2017b, 2018). SA can be also a significant component of multi-criteria decision-making techniques for sustainable building assessment (Keshavarz Ghorabaee et al. 2018).
The developed by authors analysis techniques and peculiarities to simulate and interpret obtained parameters for rock strength criterion can serve the significant tool for researcher and designer to choose the relevant values for subsequent geotechnical design and analysis of rock massif response measures applying available simulation computational packages, extent and quality of field observations. For illustration the presented case study is based on the real field data obtained by the exploration (Horák et al. 2016) of trachyte massif located in the city Ústí nad Labem (Czech Republic), $80 \mathrm{~km}$ north-west from the capital (see Figure 1).

\section{Initial random variables of rock}

The engineering geological properties are determined on the basis of field observations and laboratory tests of drilling cores (Horák et al. 2016). The statistical characteristics of relevant properties are described below. The joint surface is controlled by joint large-scale waviness, small-scale smoothness and joint alteration. The large-scale (waviness) and the small-scale (unevenness) roughness can be evaluated via the amplitude of asperities (Barton, Bandis 1990). Practically for case when the average the joint small-scale smoothness is "rough", at the same time some portions of joints are "very rough" and "slightly rough", respectively. This uncertainty is conditioned by human (error) factor in field investigation and spatial variability of joint surface as well. In this case the rating range and distribution type can serve a decision to evaluate the effect. In practice the small-scale asperities correspond the base length of several centimeters and the amplitudes are of the order of hundreds millimeters that lead to measuring problems. Therefore, the descriptive rating system is often applied (Cai et al. 2004). According the engineering geological survey (Horák et al. 2016), the joint roughness number was determined in the range from 2 (smooth, undulating) to 3 (rough or irregular, undulating). Therefore, the descriptive uniform pdf with mean value 2.5 and standard deviation 0.5 was employed in presented study. The joint 


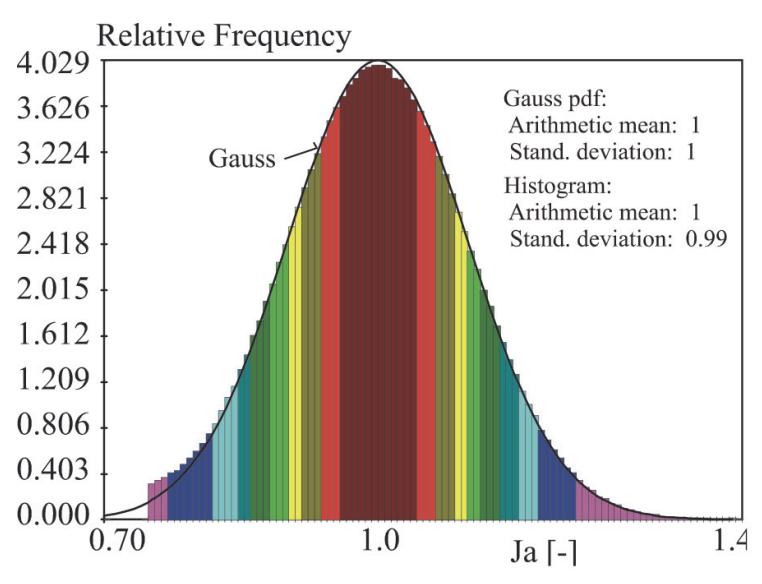

Figure 2. The histogram of $J_{a}$ parameter

alteration number, which according to Barton et al. (1974) represents the character of the joint wall contact regarding the joint filling, varies from 0.75 to 2 in the studied massif (Horák et al. 2016). Hence, the parameter $J_{a}$ was defined by the truncated Gauss probability density function (pdf) according to Cai (2010). The method of truncation is shown in Figure 2.

The randomly located discontinuities result a negative exponential distribution of spacing values versus number of occurrences (see Hudson, Priest 1983). This statement later was proved experimentally by Devkota et al. (2009) and theoretically by Stavropoulou (2014). Exponential pdf is defined by parameter $\lambda$, which was determined by experimental research as $\lambda=32,25$ and 5 (Horák et al. 2016) (see Figure 3 and Figure 4). Discontinuity parameter $\lambda$ here describes the number of discrete rock elements connected by joints in drill sample of rock.

The rock quality, or else core recovery parameter, was evaluated by determination the Rock quality designation (RQD) according to Dere et al. (1967). The non-dimensional parameter RQD (1) is defined as the ratio (in percentage) of the total length of sound core pieces of $0.1 \mathrm{~m}$ or longer to the length of the core run.

$$
R Q D=\frac{\sum \Delta L \mid \Delta L \geq 0.1 \mathrm{~m}}{\sum \Delta L} .
$$

The RQD index magnitude depends on a number of factors. Different values are obtained, for example, for a given massif for cores with different drilling orientations. The drilling technique, quality of drilling works, transportation and handling of the cores, logging etc. also influence the RQD magnitude. Differences in obtained RQD values can result in errors in rock massif classification (Pells et al. 2017). To reduce the side effects to disc a core and that

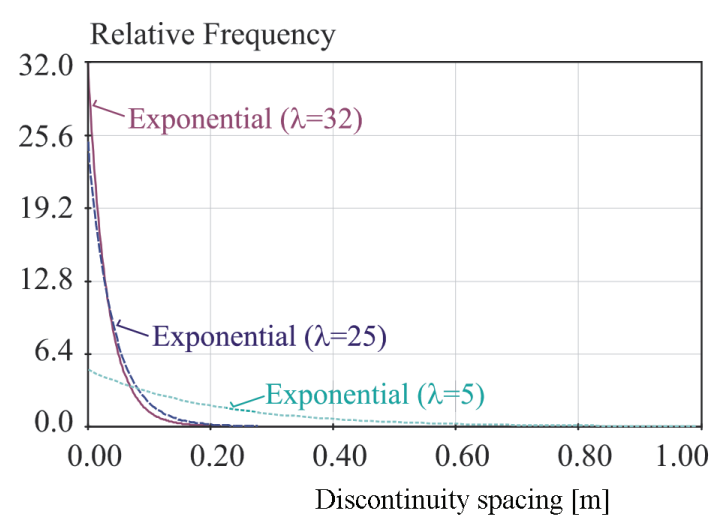

Figure 4. Pdf of discontinuity spacing

of core breakage during the drilling process, the improved methods of RQD determination are developed. Such improvements are based on incorporating more factors like angle between joint and borehole (Azimian 2016) or fracture index (Şen 2014) into RQD calculation. The utilization of new technologies, e.g. Digital Borehole Televiewers (Guo et al. 2017) or 3D laser imaging of drill core (Olson et al. 2015) in RQD determination is also investigated recently. However, the new techniques must be used with cautious, because they may produce very different RQD estimates (Zhang 2010). One must emphasize that very often RQD magnitudes determined classically according (1), employed without corrections, serve still as the only available parameter to define rock discontinuity (Zhang 2016). Random samples of discontinuity spacing were simulated by the Latin Hypercube Sampling (LHS) (McKey et al. 1979; Iman, Conover 1980) in this paper. The sets of one hundred thousand simulation runs of RQD were evaluated (see results in Figure 5 to Figure 8).

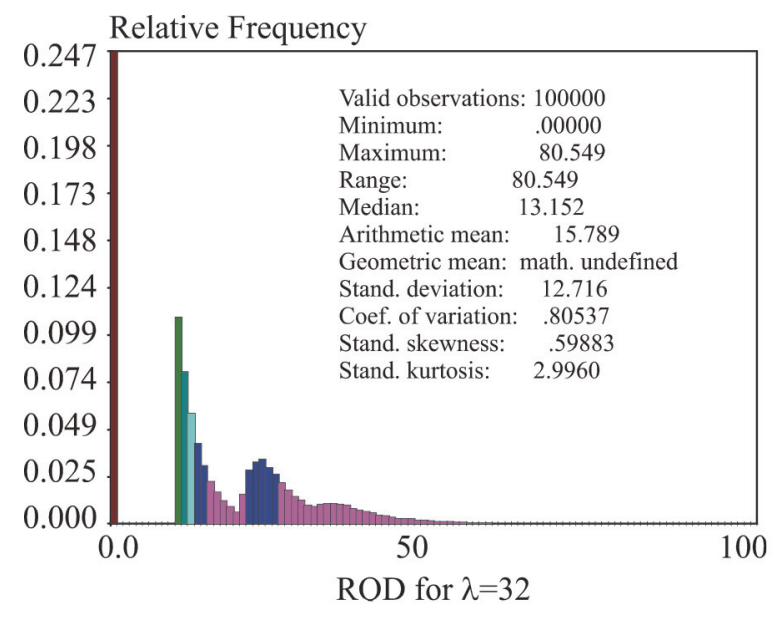

Figure 5. The histogram of RQD for $\lambda=32$

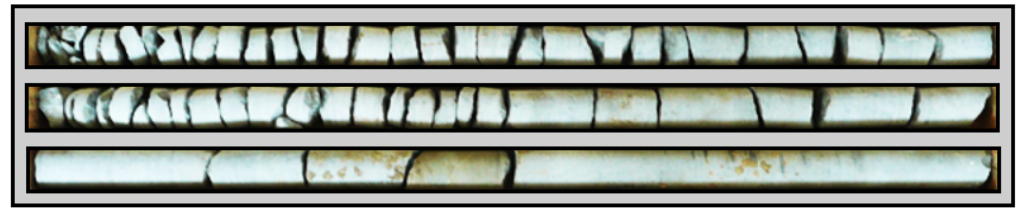

Figure 3. Core boxes of drilling from the analysed massif
$0 \div 1 \mathrm{~m}, \lambda=32$

$1 \div 2 \mathrm{~m}, \lambda=25$

$2 \div 3 \mathrm{~m}, \lambda=5$ 
Relative Frequency

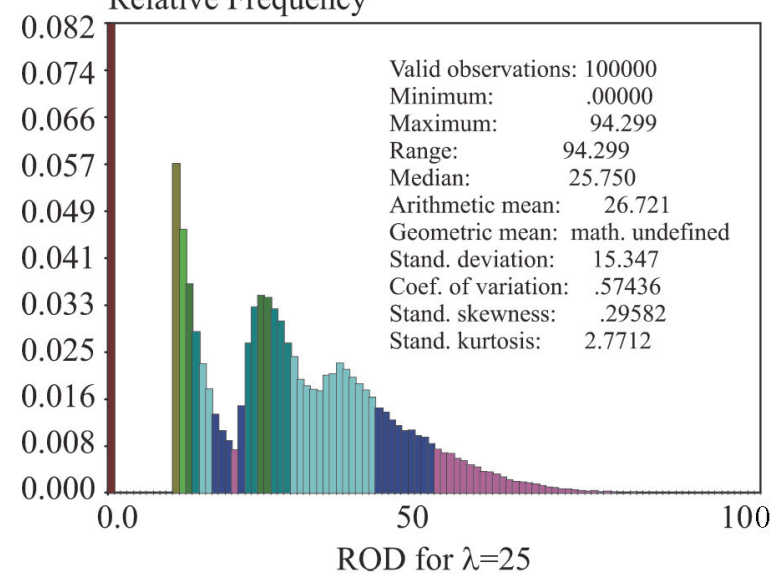

Figure 6. The histogram of RQD for $\lambda=25$

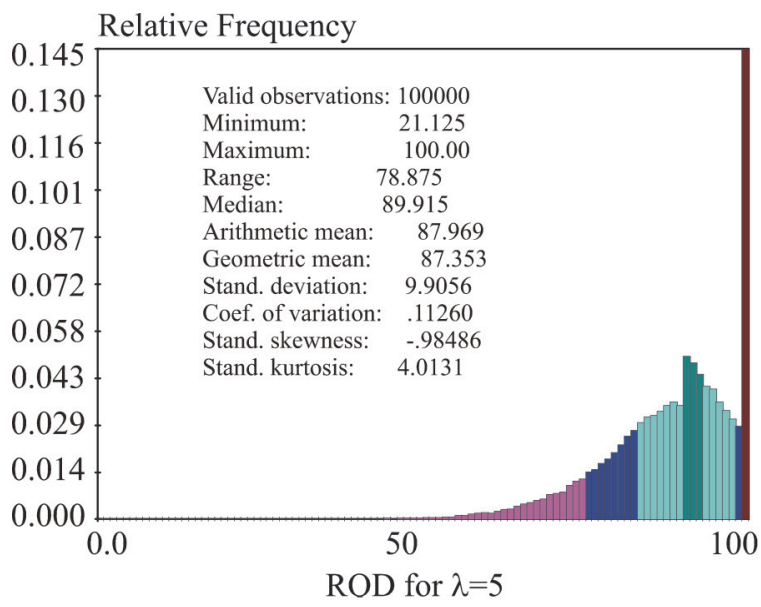

Figure 7. The histogram of RQD for $\lambda=5$

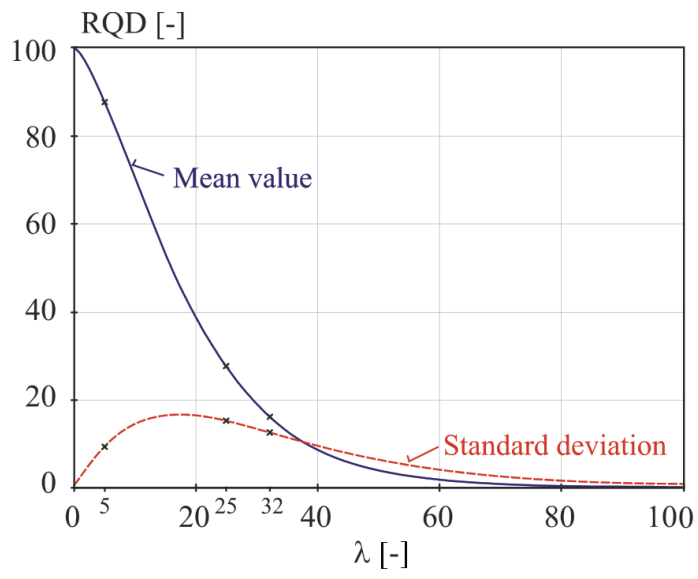

Figure 8 . The statistical analysis of RQD for $l \in(0,100)$

A characterization of employed input random variables is given in the Table 1. All input random variables are considered as statistically independent. The height of the rock slope $h$ is defined using Hermit's pdf, parameters of which are also skewness and kurtosis (Kala 2016a). The standard skewness of $h$ is 0 and standard kurtosis of $h$ is 2.4 .
The parameter $m_{i}$ is a principal one for HB failure strength criterion. In simplified way the physical meaning of this constant can be expressed via ratio of compressive and tensile strengths. The most exact magnitude of the value can be determined by processing triaxial test data. However, triaxial testing is relatively expensive and timeconsuming method. As alternative, the simplified models can be applied to estimate $m_{i}$ for rock materials (see Wang, Shen 2017; Cai 2011; Bozorgzadeh et al. 2017), or chosen the fixed magnitudes following some guideleness (Hoek, Brown 1997). The Gauss pdf of $m_{i}$ with the COV 0.125 was assigned to the guideline value $m_{i}=25$. This magnitude is in accordance with the study of Hoek (1998), conducted by the author of the HB criterion and also with Sari (2012), Lü and Low (2011) and Idris et al. (2013).

Parameter $\sigma_{c}$ was modelled by Gauss pdf with the COV 0.134 ascertained in the study of Závacký et al. (2017). The authors of study stochastically processed values measured both directly and indirectly of the rock samples taken from the analyzed rock massif. The Gauss pdf of $\sigma_{c}$ was also confirmed by the statistical analysis of laboratory tests results conducted by Sari (2012). Li et al. (2012) assigned to the $\sigma_{c}$ different COVs within the range 0.1 to 0.3 , the $\mathrm{COV}=0.25$ was employed in the study by Hoek (1998). The COV 0.134 , matching matches the range of the values reported in above listed studies, was employed in the presented calculations. The statistical characteristics of unit weight $\gamma$ of rock were expressed by the Gauss pdf (see Table 1) on the basis on the statistical evaluation of laboratory test results, presented in Závacký et al. (2017).

\section{Calculation model}

The calculation model is based on the one presented in Hoek et al. (2002). The HB failure criterion can be formulated as non-linear relationship (2) between the major and minor effective principal stresses (considering tension positive and compression negative magnitudes), reading:

$$
\sigma_{1}^{\prime}=\sigma_{3}^{\prime}-\sigma_{c i}\left(m_{b} \frac{-\sigma_{3}^{\prime}}{\sigma_{c i}}+s\right)^{a},
$$

Table 1. Input random variables

\begin{tabular}{|c|l|c|c|c|c|}
\hline No. & \multicolumn{1}{|c|}{ Pdf } & Symbol & $\begin{array}{c}\text { Mean } \\
\text { value }\end{array}$ & $\begin{array}{c}\text { Std. } \\
\text { Deviation }\end{array}$ & Units \\
\hline 1. & Hermite & $h$ & 100 & 10 & {$[\mathrm{~m}]$} \\
\hline 2. & $\begin{array}{l}\text { Discrete } \\
\text { uniform }\end{array}$ & $J_{r}$ & 2.5 & 0.5 & {$[-]$} \\
\hline 3. & $\begin{array}{l}\text { Truncated } \\
\text { Gauss }\end{array}$ & $J_{a}$ & 1 & 0.99 & {$[-]$} \\
\hline 4. & Histogram & $R Q D$ & $\begin{array}{c}\text { Figures } \\
5-8\end{array}$ & $\begin{array}{c}\text { Figures } \\
5-8\end{array}$ & {$[-]$} \\
\hline 5. & Gauss & $m_{i}$ & 25 & 3.125 & {$[-]$} \\
\hline 6. & Gauss & $\gamma$ & 24.23 & 0.2423 & {$\left[\mathrm{kN} / \mathrm{m}^{3}\right]$} \\
\hline 7. & Gauss & $\sigma_{c}$ & 134 & 18 & {$[\mathrm{MPa}]$} \\
\hline
\end{tabular}


where $\sigma_{1}$ and $\sigma_{3}$ are the major and minor effective principal stresses at failure, $\sigma_{c i}$ is the uniaxial compressive strength of the intact rock material and $s$ and $m_{b}$ are material constants, respectively. The constant $s=1$ was chosen for intact rock. The constant $m_{b}$ is the reduced value of the intact rock parameter $m_{i}$. It depends on the Geological Strength Index (GSI) and the Disturbance Factor (D) as given below:

$$
m_{b}=m_{i} \exp \left(\frac{G S I-100}{28-14 D}\right) \text {. }
$$

$D=0$ was employed in calculations. GSI system is the empiric method for characterizing jointed rock mass and determining its strength indirectly by processing data of intact rock and jointing. It has been developed many years. GSI summarize experience of field testing, processing of results and practical applications. In this case study the value of Geological strength index (GSI) was estimated according the correlation presented in Hoek et al. (2013). It reads:

$$
G S I=\frac{52 \frac{J_{r}}{J_{a}}}{\left(1+\frac{J_{r}}{J_{a}}\right)}+\frac{R Q D}{2} .
$$

The relationship (4) is based on the above mentioned RQD and on quotient $J_{r} / J_{a}$, included in the Tunneling Quality Index Q by Barton et al. (1974). This quotient represents the roughness and frictional characteristics of the joint walls or fillings. Parameters $s$ and $a$ are the auxiliary material constants for the rock mass, that are expressed by:

$$
\begin{aligned}
& s=\exp \left(\frac{G S I-100}{9-3 D}\right) \\
& a=\frac{1}{2}+\frac{1}{6}\left[\exp \left(\frac{-G S I}{15}\right)-\exp \left(-\frac{20}{3}\right)\right] .
\end{aligned}
$$

The balanced fit was done by fitting an average linear relationship to the curve generated by solving Eqn (2) for a range of minor principal stress values defined by:

$$
-\sigma_{t}<\sigma_{3}^{\prime}<-\sigma_{3, \max }
$$

This led to the following equations for the Mohr-Coulomb equivalent effective strength parameters $\varphi$ 'and $c^{\prime}$, reading:

$$
\begin{gathered}
\sin \varphi^{\prime}=\frac{6 a m_{b}\left(s+m_{b} \sigma_{3 n}^{\prime}\right)^{a-1}}{2(1+a)(2+a)+6 a m_{b}\left(s+m_{b} \sigma_{3 n}^{\prime}\right)^{a-1}}, \\
c^{\prime}=\frac{\sigma_{c i}\left[(1+2 a) s+(1-a) m_{b} \sigma_{3 n}^{\prime}\right]\left(s+m_{b} \sigma_{3 n}^{\prime}\right)^{a-1}}{(1+a)(2+a) \sqrt{1+\frac{6 a m_{b}\left(s+m_{b} \sigma_{3 n}^{\prime}\right)^{a-1}}{(1+a)(2+a)}}} .
\end{gathered}
$$

Here

$$
\sigma_{3 n}^{\prime}=\frac{\sigma_{3, \max }^{\prime}}{\sigma_{c m}^{\prime}},
$$

where the global rock mass strength $\sigma_{c m}$ is determined by:

$$
\sigma_{c m}^{\prime}=\sigma_{c i} \frac{\left(m_{b}+4 s+a\left(m_{b}-8 s\right)\right)\left(m_{b} / 4+s\right)^{a-1}}{2(1+a)(2+a)} .
$$

Selection of the appropriate magnitude of the value $\sigma_{3 \text {, max }}^{\prime}$, employed in Eqns (7) and (10), actually is a certain issue because of its complexity and therefore is related with specific application. The closed form solutions for generalized MC and HB criteria have been simulated hundreds of times with the aim to identify the magnitude, yielding the equivalent characteristic graphs (see Hoek et al. 2002). Analysis slope stability limit state solutions, corresponding wide range of slip shapes in concert with variation of rock mechanical properties via the Bishop's circular failure method, was summarized by Hoek et al. (2002). It reads:

$$
\frac{\sigma_{3, \max }^{\prime}}{\sigma_{c m}}=0.72\left(\frac{\sigma_{c m}^{\prime}}{\gamma h}\right)^{-0.92} .
$$

Note that effective values in above given formulae are denoted by apostrophe, which is omitted for simplicity further.

\section{Sensitivity analysis}

One of the most effective methods of stochastic global SA is Sobol's sensitivity analysis (SSA). It is based on the total decomposition of the variance of the output variable into parts with increasing dimension of input variables (Sobol' 1993, 2001). The SSA input variables for characterization the angle of shearing resistance $\varphi$ and equivalent cohesion $c$ (random outputs $Y$ ) are presented in Table 1 (random inputs $X_{i}$ ). In the presented study, the sensitivity measures were performed according to Eqn (13).

Sobol's first order sensitivity indices may be expressed by Saltelli et al. (2004):

$$
S_{i}=\frac{V\left(E\left(Y \mid X_{i}\right)\right)}{V(Y)} .
$$

$S_{i}$ is a measure of the first order (e.g. additive) effect, i.e. the main effect of $X_{i}$ on the model output $Y$. The sum of all $S_{i}$ is equal to 1 for additive models, and less than 1 for non-additive models. The difference $1-\sum_{i} S_{i}$ is an indicator of the presence of interactions in the model.

The LHS method was applied to generate input random variables. Ten thousand LHS runs were used for the evaluation of $E\left(Y \mid X_{i}\right)$ in Eqn (13), and another ten thousand LHS runs were used for the evaluation of $V\left(E\left(Y \mid X_{i}\right)\right)$. The variance $V(Y)$ was evaluated with one hundred thousand LHS runs. 


\section{Sensitivity analysis results}

The SSA analyzes the effects of the variability of inputs described in Table 1 on the outputs $\varphi$ and $c$. Global SA results of $\varphi$ and $c$ are displayed using pie charts. $360^{\circ}$ represents the sum of all indices 1 (see e.g. Kala 2016b). All first-order (13) sensitivity indices $S_{i}$ were evaluated. The other higher-order indices were not evaluated, because the sum of all first-order indexes $S_{i}$ was equal approximately to 1 .

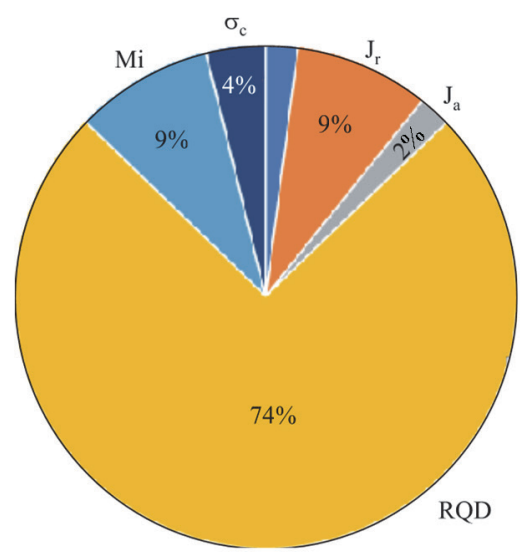

Figure 9. The results of sensitivity analysis of $\varphi$ for $\lambda=32$

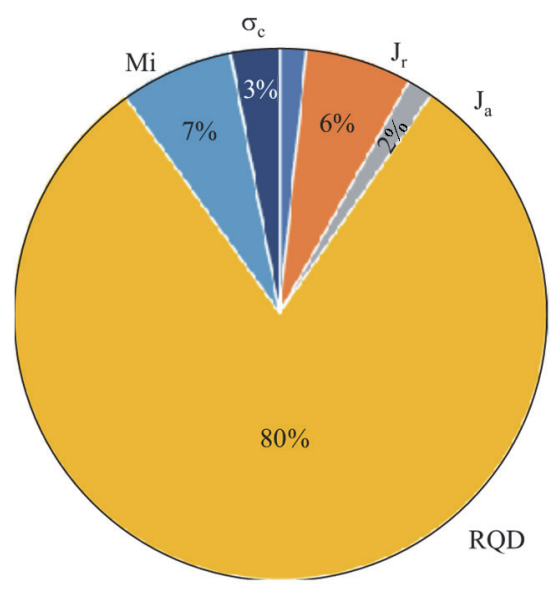

Figure 10. The results of sensitivity analysis of $\varphi$ for $\lambda=25$

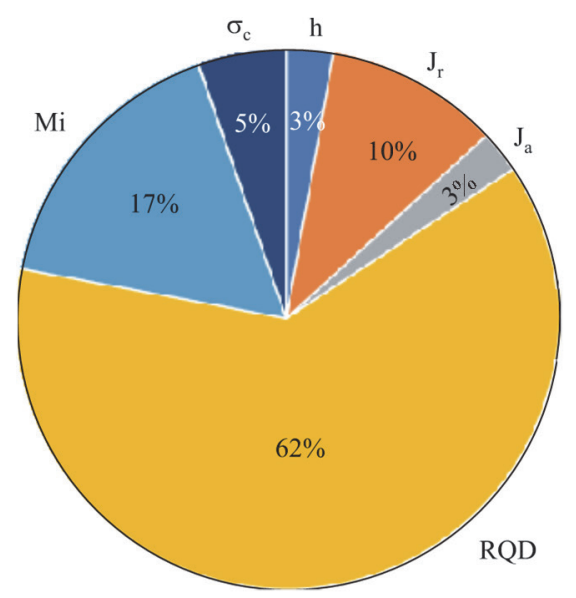

Figure 11. The results of sensitivity analysis of $\varphi$ for $\lambda=5$

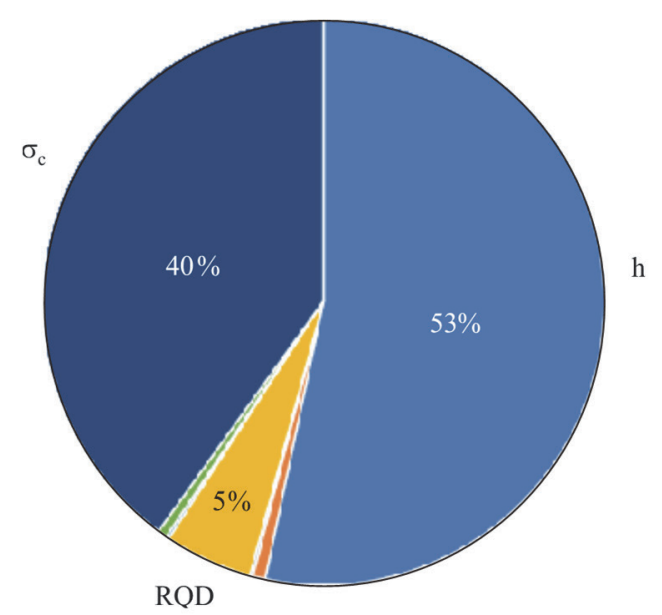

Figure 12 . The results of sensitivity analysis of $c$ for $\lambda=32$

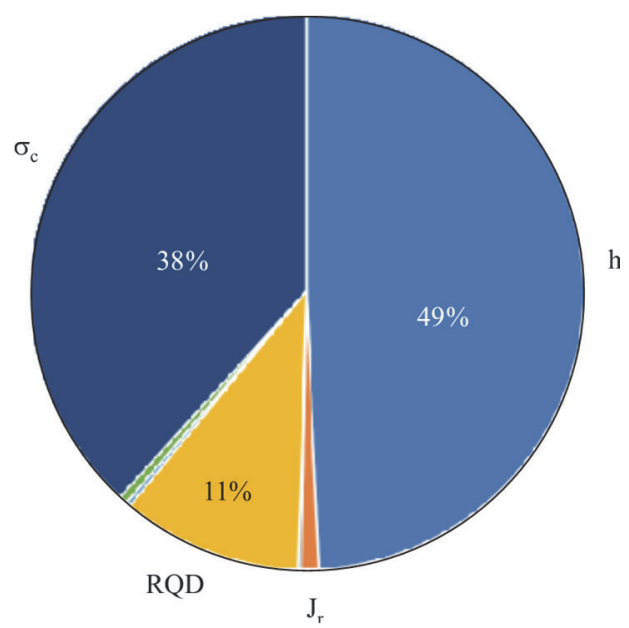

Figure 13. The results of sensitivity analysis of $c$ for $\lambda=25$

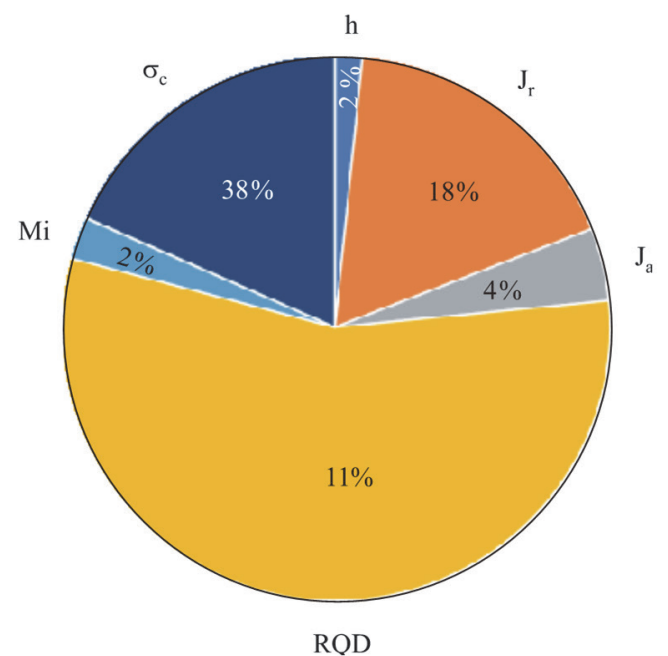

Figure 14. The results of sensitivity analysis of $c$ for $\lambda=5$ 
It is apparent from the charts in Figures 9-14 that the first-order effects are crucial, the higher-order effects are negligible as $1-\sum_{i} S_{i} \approx 0$.

\section{Summary and Conclusions}

Results of Sobol's sensitivity analysis (SSA), quantifying the effect of jointed rock massif properties on the equivalent MC parameters $\varphi$ and $c$ are presented in this article. SSA is used to increase to confidence in the model, by providing an understanding of how the model response variables $\varphi$ and $c$ respond to change in the inputs. The MC criterion parameters $\varphi$ and $c$ were obtained by procedure of fitting an average $\mathrm{MC}$ linear relationship to the nonlinear HB one.

The pie charts on Figures 9-14 represent results of SSA, where the sum of all indices is 1 . The wedges of the pie chart represent in percent the effects of the variability of inputs on the output.

SSA results visualized on the two groups of three pie charts refers to the three calculations executed with RQD with different stochastic variability. Different variability of RQD (three histograms of RQD) in each of those three calculations was caused by the different discontinuity spacing observed on first 3.0 meters of the examined drilling core. The variability of RQD is dependent on the value of $\lambda$, where $\lambda$ is the average number of discontinuities per meter. The other random inputs were not changed in these three variants of SSA.

The statistical analysis (mean value and standard deviation (Std)) of RQD was performed for $\lambda \in(0,100)$. The $\mathrm{RQD}$ has zero random variability $(\mathrm{Std}=0)$ in limit cases $\lambda=0$ and/or $\lambda=100$. The three variants (realistically occurring in practice) of discontinuity spacing were analyzed more detailed. The three variants of discontinuity spacing simulated by the LHS led to the three exponential distributions with different variability due to parameter $\lambda=5$, 25,32 . The highest variability (Std $=15.3$ ) was observed in case of the intermediate discontinuity spacing value defined by the parameter $\lambda=25$. The other two distributions exhibited lower variability. In the case of distribution defined by $\lambda=32$, the variability was described by Std $=12.7$ and that of in case of $\lambda=5$ by Std $=9.9$, respectively. The LHS simulations show that in samples with higher number of discontinuities the realizations of RQD closer to zero value are more probably to occur. In samples simulated with lower values of discontinuities $(\lambda=5)$, the realizations of RQD values are more often cumulated closer to the value of 100 .

The first analyzed output is the equivalent angle of shearing resistance $\varphi$ obtained via the described calculation model. The results (Figures 9-11) show, that as the RQD variability decreases, it's influence decreases. As same, with decreasing influence of RQD variability, the influence of variability of the joint surface and joint alteration increases. With decreasing influence of RQD variability, the influence variability of parameters of intact rock $m_{i}$ and $\sigma_{c}$ increases.
The second analyzed output is the equivalent cohesion $c$. The SSA of $c$ is very sensitive to the parameter $\lambda$, see Figures $12-13$. The SSA results are conditioned by the nonlinear relationship between $c$ and variability of RQD. The discontinuity spacing distribution defined by the parameter $\lambda=5$ leads to higher RQD values, demonstrating the nonlinear relationship with $c$. In case of lower RQD values, the variability of the height of slope and of the intact rock strength is becoming more important.

The upper limit of confining stress, over which the relationship between the $\mathrm{HB}$ and MC criteria was considered, was determined via the correlation dependent on the height of slope (Hoek et al. 2013). This step allowed to introduce the variability of the height of the massif as the input to the SSA, which leads to significant results. The model exhibits linear regression dependence $(R=0.53)$ of the cohesion versus the height of the massif, and consequently that of versus the $\sigma_{3, \max }^{\prime}(R=0.71)$. Whereas, no significant dependence of the angle of shearing resistance $\varphi$ versus the height of slope was identified. It explains the fact, that both analyzed outputs have different sensitivity on the same inputs with same variability. In general, it depends both on the variability of the input parameters and on the calculation model, which reflects how changes of input variable values affect the analyzed outcome value.

An application of the computational model based proposed by Hoek et al. (2002) suits well for the aim, transforming $\mathrm{HB}$ strength parameters to MC ones. MC strength model allows to apply simulation tools based on MC criterion for soils.

The presented article demonstrates the application of SSA for investigated case study, often met in engineering practice one, when the description of discontinuity of rock drill samples is the only known parameter. Due rock nature and usual rock mass investigation possibilities and peculiarities, the input parameters of computational model need to be specified via stochastic evaluation. The results of current investigation lead to better understanding of the problem and serves a background for interpretation of obtained strength parameters. Presented techniques serves a reliable tool to designer for choosing rock mass design values with high cautiousness under available amount of data.

\section{Acknowledgements}

This work was supported by the research project No. FV10505 of Ministry of Industry and Trade of the Czech Republic and under the project No. LO1408 "AdMaS UP Advanced Materials, Structures and Technologies", supported by Ministry of Education, Youth and Sports under the "National Sustainability Programme I".

\section{Author Contributions}

Jan Štefaňák and Zdeněk Kala introduced idea of the study and managed development of the data analysis. Jan Štefanák was responsible for data collection and analysis. All the authors were responsible for results interpretation and preparation of manuscript of the article. 


\section{Funding}

This work was supported by the research project No. FV10505 of Ministry of Industry and Trade of the Czech Republic and project No. LO1408 "AdMaS UP".

\section{Disclosure Statement}

Authors have not any competing financial, professional, or personal interests from other parties.

\section{References}

Azimian, A. 2016. A new method for improving the RQD determination of rock core in Borehole, Rock Mechanics and Rock Engineering 49(4): 1559-1566.

https://doi.org/10.1007/s00603-015-0789-8

Barton, N. R.; Bandis, S. C. 1990. Review of predictive capability of JRC-JCS model in engineering practice, in Proceedings of the International Symposium on Rock Joints, 1990, Rotterdam, Netherlands, 603-610.

Barton, N.; Lien, R.; Lunde, J. 1974. Engineering classification of rock masses for the design of tunnel support, Rock Mechanics 6(4): 182-239. https://doi.org/10.1007/BF01239496

Borgonovo, E.; Plischke, E. 2016. Sensitivity analysis: A review of recent advances, European Journal of Operational Research 248: 869-887. https://doi.org/10.1016/j.ejor.2015.06.032

Bozorgzadeh, N.; Yanagimura, Y.; Harrison, J. 2017. Effect of small numbers of test results on accuracy of Hoek-Brown strength parameter estimations: A statistical simulation study, Rock Mechanics and Rock Engineering 50(12): 3293-3305. https://doi.org/10.1007/s00603-017-1352-6

Brinkgreve, R. B. J.; Bakker, H. L. 1991. Non-linear finite element analysis of safety factors, in Proceedings of the $7^{\text {th }}$ International Conference on Computer Methods and Advances in Geomechanics, 1991, Cairns, Australia, 1117-1122.

Cai, M. 2010. Practical estimates of tensile strength and HoekBrown strength parameter $\mathrm{m}_{\mathrm{i}}$ of Brittle Rocks, Rock Mechanics and Rock Engineering 43(2): 167-184.

https://doi.org/10.1007/s00603-009-0053-1

Cai, M. 2011. Rock mass characterization and rock property variability considerations for tunnel and cavern design, Rock Mechanics and Rock Engineering 44: 379-399. https://doi.org/10.1007/s00603-011-0138-5

Cai, Y.; Esaki, T.; Jiang, Y. 2004. A rock bolt and rock mass interaction model, International Journal of Rock Mechanics and Mining Sciences 41(7): 1055-1067.

https://doi.org/10.1016/j.ijrmms.2004.04.005

Dere, D.; Hendron, A.; Patton, F.; Cording, E. 1967. Design of surface and near surface constructions in rock, in Proceedings of the $8^{\text {th }}$ U. S. Symposium on Rock Mechanics, 1967, New York, USA, 237-302.

Devkota, K.; Ham, J-E.; Kim, G-W. 2009. Characteristics of discontinuity spacing of Yeongdeok granite, Geosciences Journal 13(2): 161-165. https://doi.org/10.1007/s12303-009-0015-3

Guo, H.-S.; Feng, X.-T.; Li, S.-J.; Yang, C.-X; Yao, Z.-B. 2017. Evaluation of the integrity of deep rock masses using results of digital borehole televiewers, Rock Mechanics and Rock Engineering 50(6): 1371-1382.

https://doi.org/10.1007/s00603-017-1173-7

Hoek, E. 1998. Reliability of Hoek-Brown estimates of rock mass properties and their impact on design, International Journal of Rock Mechanics and Mining Sciences 35(1): 63-68. https://doi.org/10.1016/S0148-9062(97)00314-8
Hoek, E.; Brown, E. T. 1997. Practical estimates of rock mass strength, International Journal of Rock Mechanics and Mining Sciences 34(8): 1165-1186.

https://doi.org/10.1016/S1365-1609(97)80069-X

Hoek, E.; Carranza-Torres, C.; Corkum, C. 2002. Hoek-Brown failure criterion - 2002 edition, in Proceedings of NARMSTAC Conference, 2002, Toronto, Canada, 267-273.

Hoek, E.; Carter, T.; Diederichs, M. 2013. Quantification of the geological strength index chart, in $47^{\text {th }}$ U.S. Rock Mechanics/ Geomechanics Symposium, 23-26 June 2013, San Francisco, CA, USA.

Horák, V.; Závacký, M.; Štefaňák, J. 2016. Výzkumná zpráva č. HS12645008L: Laboratorní zkoušky skalních hornin. Brno: Vysoké učení technické v Brně, Fakulta stavební, AdMaS Pokročilé stavební materiály, konstrukce a technologie (in Czech).

Hudson, J. A.; Priest, S. D. 1983. Discontinuity frequency in rock masses, International Journal of Rock Mechanics and Mining Sciences \& Geomechanics Abstracts 20(2): 73-89.

https://doi.org/10.1016/0148-9062(83)90329-7

Idris, M.; Basarir, H.; Nordlund, E.; Wettainen, T. 2013. The probabilistic estimation of rock masses properties in Malmberget mein, Sweden, The Electronic Journal of Geotechnical Engineering 18: 269-287.

Iman, R. C.; Conover, W. J. 1980. Small sample sensitivity analysis techniques for computer models with an application to risk assessment, Communications in Statistics - Theory and Methods 9(17): 1749-1842. https://doi.org/10.1080/03610928008827996

Kala, Z. 2016a. Global interval sensitivity analysis of Hermite probability density function percentiles, International Journal of Mathematical Models and Methods in Applied Sciences 10: 373-380.

Kala, Z. 2016b. Global sensitivity analysis in stability problems of steel frame structures, Journal of Civil Engineering and Management 22(3): 417-424. http://dx.doi.org/10.3846/13923730.2015.1073618

Kala, Z.; Valeš, J. 2017a. Global sensitivity analysis of lateraltorsional buckling resistance based on finite element simulations, Engineering Structures 134: 37-47. http://dx.doi.org/10.1016/j.engstruct.2016.12.032

Kala, Z.; Valeš, J. 2017b. Sensitivity assessment and lateral-torsional buckling design of I-beams using solid finite elements, Journal of Constructional Steel Research 139: 110-122. https://doi.org/10.1016/j.jcsr.2017.09.014

Kala, Z.; Valeš, J. 2018. Imperfection sensitivity analysis of steel columns at ultimate limit state, Archives of Civil and Mechanical Engineering 18(4): 1207-1218. https://doi.org/10.1016/j.acme.2018.01.009

Keshavarz Ghorabaee, M. K.; Amiri, M.; Zavadskas, E. K.; Antucheviciene, J. 2018. A new hybrid fuzzy MCDM approach for evaluation of construction equipment with sustainability considerations, Archives of Civil and Mechanical Engineering 18(1): 32-49. https://doi.org/10.1016/j.acme.2017.04.011

Li, A. J.; Cassidy, M. J.; Wang, Y.; Merifield, R. S.; Lyamin, A. V. 2012. Parametric Monte Carlo studies of rock slopes based on the Hoek-Brown failure criterion, Computers and Geotechnics 45: 11-18. https://doi.org/10.1016/j.compgeo.2012.05.010

Liang, J.; Ding, Z.; Li, J. 2017. A probabilistic analyzed method for concrete fatigue life, Probabilistic Engineering Mechanics 49: 13-21. http://dx.doi.org/10.1016/j.probengmech.2017.08.002

Lü, Q.; Low, B. K. 2011. Probabilistic analysis of underground rock excavations using response surface method and SORM, Computers and Geotechnics 38(8): 1008-1021. https://doi.org/10.1016/j.compgeo.2011.07.003 
McKey, M. D.; Conover, W. J.; Beckman, R. J. 1979. A comparison of the three methods of selecting values of input variables in the analysis of output from a computer code, Technometrics 21(2): 239-245. https://doi.org/10.2307/1268522

Olson, L.; Samson, C.; Mckinnon, S. D. 2015. 3-D laser imaging of drill core for fracture detection and rock quality designation, International Journal of Rock Mechanics and Mining Sciences 73: 156-164. https://doi.org/10.1016/j.ijrmms.2014.11.004

Palmström, A. 2002. Measurement and characterization of rock mass jointing, in V. M. Sharma, K. R. Saxena (Eds.). In-situ characterization of rock mass jointing. Oslo: A. A. Balkema Publishers, 49-98.

Pejkowski, L. 2017. On the material's sensitivity to non-proportionality of fatigue loading, Archives of Civil and Mechanical Engineering 17(3): 711-727. http://dx.doi.org/10.1016/j.acme.2016.09.010

Pells, P. J.; Bieniawski, Z. T.; Hencher, S. R.; Pells, S. E. 2017. Rock quality designation (RQD): time to rest in peace, Canadian Geotechnical Journal 54(6): 825-834. https://doi.org/10.1139/cgj-2016-0012

Saltelli, A.; Annoni, P.; Azzini, I.; Campolongo, F.; Ratto, M.; Tarantola, S. 2010. Variance based sensitivity analysis of model output. Design and estimator for the total sensitivity index, Computer Physics Communications 181: 259-270. http://dx.doi.org/10.1016/j.cpc.2009.09.018

Saltelli, A.; Chan, K.; Scott, E. M. 2004. Sensitivity analysis. Wiley series in probability and statistics. New York: John Wiley and Sons. 475 p.

Sari, M. 2012. Stochastic estimation of the Hoek-Brown strength parameters using spreadsheet models, in EUROCK 2012 ISMR International Symposium, 28-30 May 2012, Stockholm, Sweden.

Şen, Z. 2014. Rock quality designation-fracture intensity index method for geomechanical classification, Arabian Journal of Geosciences 7(7): 2915-2922. https://doi.org/10.1007/s12517-013-0975-5

Sobol', I. M. 1993. Sensitivity analysis for non-linear mathematical models, Mathematical Modelling and Computational Experiment 1: 407-414. Translated from Russian: I. M. Sobol'. 1990. Sensitivity estimates for nonlinear mathematical models, Matematicheskoe Modelirovanie 2: 112-118.

Sobol', I. M. 2001. Global sensitivity indices for nonlinear mathematical models and their Monte Carlo estimates, Mathematics and Computers in Simulation 55(1-3): 271-280. https://doi.org/10.1016/S0378-4754(00)00270-6

Stavropoulou, M. 2014. Discontinuity frequency and block volume distribution in rock masses, International Journal of Rock Mechanics and Mining Sciences 65: 62-74. https://doi.org/10.1016/j.ijrmms.2013.11.003

Vessia, G.; Kozubal, J.; Pula, W. 2017. High dimensional model representation for reliability analyses of complex rock-soil slope stability, Archives of Civil and Mechanical Engineering 17(4): 954-963. http://dx.doi.org/10.1016/j.acme.2017.04.005

Wang, W.; Shen, J. 2017. Comparison of existing methods and a new tensile strength based model in estimating the HoekBrown constant $\mathrm{m}_{\mathrm{i}}$ for intact rocks, Engineering Geology 224: 87-96. https://doi.org/10.1016/j.enggeo.2017.05.008

Závacký, M.; Štefaňák, J.; Horák, V.; Miča, L. 2017. Statistical estimate of uniaxial compressive strength of rock based on Shore hardness, in EUROCK 2017 ISMR International Symposium, 2017, Prague, Czech Republic Republic, 248-255.

https://doi.org/10.1016/j.proeng.2017.05.178
Zhang, L. 2010. Estimating the strength of jointed rock masses, Rock Mechanics and Rock Engineering 43(4): 391-402. https://doi.org/10.1007/s00603-009-0065-x

Zhang, L. 2016. Determination and applications of rock quality designation (RQD), Journal of Rock Mechanics and Geotechnical Engineering 8(3): 389-397.

https://doi.org/10.1016/j.jrmge.2015.11.008 